\title{
Analysis of salient-pole synchronous generators operating in single-phase condition
}

\author{
C. Spagnolo, S. Nuzzo, G. Serra, C. Gerada, M. Galea
}

\begin{abstract}
The power generation industry has recently started to invest interest and focus on the single-phase operation of traditional three-phase, wound-field, synchronous generators. This is partially due to a combination of customer requirements and the need to understand the extent of flexibility in their current products. This paper deals with an in-detail analysis of a salient-pole, wound-field, three-phase synchronous generator operating in single-phase condition, at unity power factor. The particular $400 \mathrm{kVA}$ alternator is first analysed via the classical analytical equations and the results compared with finiteelement and available experimental measurements for validation purposes. The tools developed in this stage are then used to analyse the generator under study when it operates in singlephase condition with different values of load. In this work, it can be observed how single-phase operation of synchronous generators can result in an increase of the power-per-phase performance and that, with the appropriate winding configuration, the machine can be used in single-phase operation with a reduced loading.
\end{abstract}

Index Terms-Analytical modelling, single-phase operation, salient-poles, synchronous generators

\section{INTRODUCTION}

$\mathrm{T}$ HE proven performance capability and its long history in the field of power generation make the wound-field, salient-pole, synchronous generator (SG) the natural choice when an efficient and reliable electrical machine is required for generation applications [1]. In general, such technologies are commonly used for three phase $(3 \theta)$ applications. There is however an ever-increasing demand for single phase $(1 \theta)$ systems. While dedicated, $1 \theta$ SGs have been around for decades, however commonly-available $1 \theta$ SGs are usually only available for comparatively small output and low speed applications [2]. Therefore a lot of interest is today being invested in $1 \theta$ generation systems rated for higher power applications. While this would be optimally done by developing new, dedicated $1 \theta$ generators from scratch, however a number of SG manufactures have recently begun to investigate the migration of existing $3 \theta$ products to $1 \theta$ operation. This is due to particular customer requirements, to the ever-changing market demands and to the historic inertia/reluctance of industrial organizations relative to launching new product research programs after having heavily invested in other products. One of the main aims of

C. Spagnolo, S. Nuzzo, C. Gerada and M. Galea are with the Power Electronics, Machine and Control Group, University of Nottingham, Nottingham, UK (email: ezzcs2@nottingham.ac.uk).

G. Serra is with the Department of Electrical, Electronic, and Information Engineering, University of Bologna, Bologna, Italy, (giovanni.serra@unibo.it).

C. Gerada is with the Power Electronics, Machine and Control Group, University of Nottingham Ningbo, Ningbo, China, (eezcg@nottingham.ac.uk). such efforts is that of investigating the flexibility of such translations in the design and to identify the limits related to these considerations. As will be shown in this paper, $1 \theta$ operation of $3 \theta$ SGs can result in an increase of the powerper-phase of the machine and that, with minimum disruption to the design mainly based on an appropriate re-wiring, certain machines can achieve an excellent performance in $1 \theta$ operation with reduced loading [2].

The analysis carried out in this paper aims at providing a better understanding of the performance of $3 \theta$ SGs operating under $1 \theta$ loading, as opposed to the more classical $3 \theta$ operation of such machines. The main consideration which this paper is based on, is the fact that during such operation, a $1 \theta$ alternating current is flowing in the stator winding and a pulsating wave of mmf is thus produced. This field can be separated into two components, namely 1) a component rotating in the same direction as the rotor, referred to as "positive field" and 2) a component that rotates in the opposite direction at relative double the speed, referred to as "negative field". The second component produces an alternate magnetic flux into the field windings, flowing from the rotor poles and superimposing to the main excitation field. Similarly to the above, this field can be divided into a "positive" and a "negative" component. The latter features the same speed as the main rotor field. The positive field travels at a speed which is three times that of the main rotor field, generating in the stator windings an EMF with a frequency that is three times higher than the main frequency. Therefore, it is clear that the negative sequence of the field needs to be damped by an additional winding which is typically placed in slots distributed along the salient poles of such machines. In fact, the flux density's negative component induces a voltage at double the supply frequency in the rotor damper bars, producing currents which oppose the asymmetric armature reaction due to the $1 \theta$ operation. Considering all the above, then this paper focuses on the analysis of the current flow induced in the damper winding and the associated losses. The paper starts with an in-detail modelling and analysis of a $3 \theta$, salient-pole SG, with special focus on its $1 \theta$ operating condition. A preliminary sizing procedure of SGs is described in Section II, using a set of equations to identify the equivalent values of a $3 \theta$ machine operating in $1 \theta$ conditions. A preliminary set of analytical equations is implemented to estimate the value of excitation current under load variations. In Section III, after a brief description of the machine under study, an in-detail FiniteElement (FE) analysis of the considered 400kVA SG is performed and results compared to the analytical model. In Section IV, one method for evaluating the field current at different loadings is described. In order to validate the proposed methodologies, experimental tests are finally performed on the SG under $1 \theta$ loading. 


\section{ANALYTICAL CONSIDERATIONS OF THREE-PHASE SGS WORKING IN SINGLE-PHASE CONDITION}

The analysis procedure of SGs, designed for 'normal' $3 \theta$ operation but also aimed at supplying $1 \theta$ loads, requires some preliminary considerations, focused on the particular winding configuration. In fact, the $3 \theta$ stator winding of such machines has to be connected in such a way that it appropriately works also in $1 \theta$ operation. An easy way of obtaining a $1 \theta$ SG is to disconnect one phase and series-connect the remaining two phases. In this condition, the $1 \theta$ generated power $P_{l}$ is that shown in (1), where $V_{p h}$ is the phase voltage, $V_{l l}$ is the line-toline voltage and $I$ is the current flowing in the seriesconnected phases. The output ratio between $P_{1}$ and the $3 \theta$ power $P_{3}$ is therefore given by (2) and the ohmic losses in the stator windings in the case when $I_{1}=I_{3}=I$ are related as described in (2).

$$
\begin{aligned}
& P_{1}=\sqrt{3} V_{p h} I=V_{l l} I \\
& \frac{P_{1}}{P_{3}}=\frac{1}{\sqrt{3}}=0.578
\end{aligned}
$$

If it was to be assumed that the given dimensions allowed for equal losses in the stator windings for both the $1 \theta$ and $3 \theta$ cases, the current ratio shown in (3) would be permissible and thus the power ratio is that given in (4).

$$
\begin{gathered}
\frac{I_{1}}{I_{3}}=\sqrt{\frac{3}{2}}=1.225 \\
\frac{P_{1}}{P_{3}}=\frac{V_{l l} I_{1}}{\sqrt{3} V_{l l} I_{3}}=\frac{1}{\sqrt{2}}=0.717
\end{gathered}
$$

Considering the above, then additional analytical considerations can be carry out in order to calculate the value of the excitation current $I_{F}$ needed to feed the different loading levels while keeping the output voltage constant. The starting point of this design stage is represented by the $B-H$ characteristic of the lamination sheet. The accuracy of this curve, inherently to its real behavior in the electrical machine under analysis, is of paramount importance for the accuracy of the following calculations. In particular, given the geometrical dimensions of the SG, it is possible to proceed with the evaluation of the magnetomotive ( $\mathrm{mmf}$ ) drops along the principal flux lines.

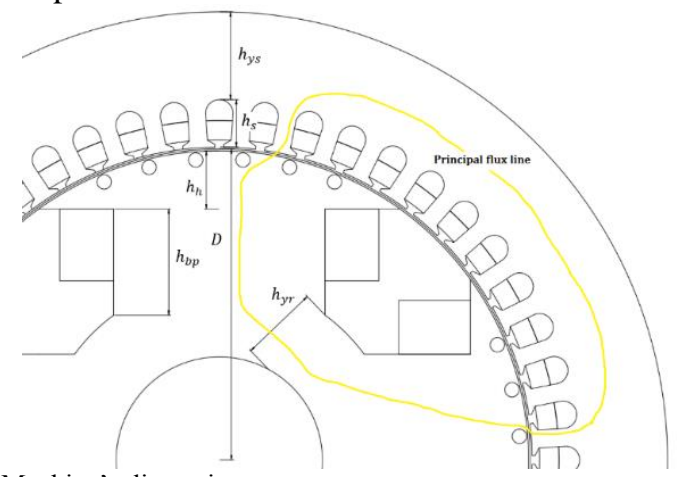

A general schematic of the machine under analysis is illustrated in Fig. 1. The calculations related to the mmf drops and thus those relevant to the evaluation of the necessary Ampere-turns are given in (5)-(9), where the Ampere's law is applied along the main flux line shown in Fig. 1. The main aim of this design stage is that of identifying a direct relationship between the total $\mathrm{mmfs}$ needed in $3 \theta$ and $1 \theta$ operations, as described in (2). In order to do this, the first step is to evaluate the Carter's coefficient $k_{c s}$ [3] for the magnetic voltage drop in the airgap, calculated with the expression, as described by (5), where $\mu_{0}$ is the permeability of the free space, $B_{M}$ is the maximum value of the airgap flux density waveform (which can be assumed in this analysis on the basis of well-known typical values) and $\delta_{\min }$ is the airgap length in correspondence of the d-axis.

$$
\theta_{\delta}=\frac{1}{\mu_{0}} B_{M} K_{c s} \delta_{\min }
$$

By using the same principle, the magnetic voltage drops in the stator tooth, the stator and rotor yokes and the salientpole can be evaluated. These are described by equations (6)(9), where $H_{T m}, H_{y s m}, H_{y r m}, H_{p e}$ and $H_{b p}$ are the chosen average values of the magnetic field inside the respective parts of the considered machine.

$$
\begin{gathered}
\theta_{T}=H_{T m} h_{s} \\
\theta_{y s}=H_{y s m} L_{y s} \\
\theta_{y r}=H_{y r m} L_{y r} \\
\theta_{p}=H_{p e} h_{h}+H_{b p} h_{b p}
\end{gathered}
$$

Having determined all the mmfs drops, it becomes finally possible to calculate the total $\mathrm{mmf}$ that has to be provided by one pole in order to compensate for these drops. This is done as shown in (10), while in (11) the value of the field current needed at no-load condition (given the number of turns-perpole $N_{t p}$ ) is determined.

$$
\begin{gathered}
\theta_{t o t}=\theta_{\delta}+\theta_{T}+\frac{\theta_{y s}}{2}+\frac{\theta_{y r}}{2} \\
I_{F 0}=\frac{\theta_{t o t}}{N_{t p}}
\end{gathered}
$$

The calculations shown above are well-known and very widely used for a first, preliminary sizing of a generic electrical machine operating in normal condition [4-7]. However, for $1 \theta$ operations of the SG, some additional considerations have to be taken into account. In particular, using (2) and knowing the value of the current in one phase of the armature winding in $3 \theta$ condition, it is possible to determine the current needed to supply the $1 \theta$ load, as described in (12).

$$
I_{a}=\frac{P_{1} / \sqrt{3}}{\sqrt{3} V}
$$

Fig. 1. Machine's dimensions. 
This observation can also be seen in the Arnold-Blondel diagram of Fig. 2 where, under the assumption of linear behavior of the ferromagnetic materials, it can be seen that the value of $m m f_{a}$ is reduced by $\sqrt{3}$.

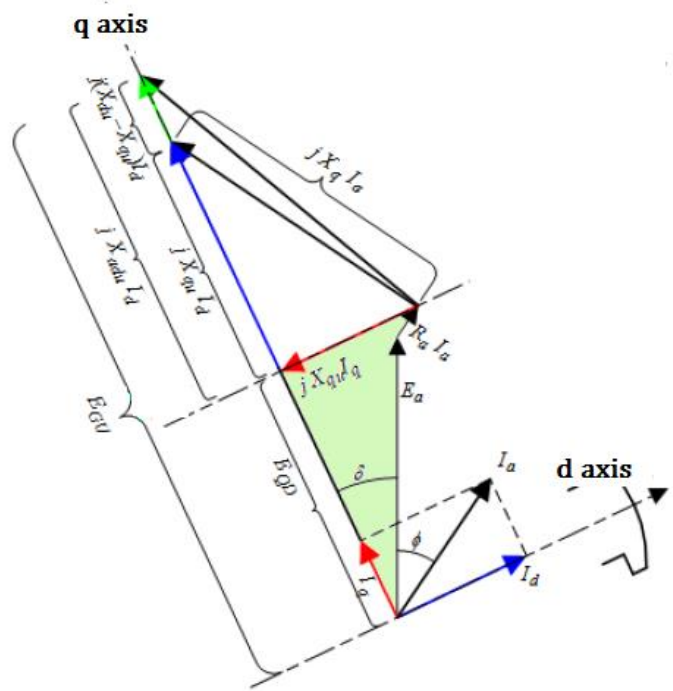

Fig. 2. Arnold-Blondel diagram for synchronous generators.

Proceeding with the calculations of the $d$ - and q-axis currents (as shown in (13) and (14)), the value of the no-load emf of the unsaturated machine can be evaluated by (15).

$$
\begin{gathered}
\hat{I}_{d}=I_{a} \sin (\delta-\phi) e^{j\left(\delta-\frac{\pi}{2}\right)} \\
\hat{I}_{q}=I_{a} \cos (\delta-\phi) e^{j \delta} \\
\hat{E}_{g u}=E_{a}+R_{a} \hat{I}_{a}+j I_{q} X_{q u}+j I_{d} X_{d u}
\end{gathered}
$$

In (15), $\tilde{\mathrm{I}}_{\mathrm{a}}=I_{a} e^{j \Phi}, \mathrm{R}_{a}$ is the armature resistance, $X_{q u}$ is the unsaturated $q$-axis reactance and $X_{d u}$ is the unsaturated $d$-axis reactance. Having determined the above quantities, it is now possible to calculate the value of the mmf that needs to be supported by the rotor when the machine is unsaturated. This is given by using (16), where $\mathrm{E}_{\text {gap }}$ is obtained from the noload characteristic and $\varphi_{n}$ is the rated flux in the airgap.

$$
\theta_{g u}\left(\varphi_{n}\right)=\frac{\left|E_{g u}\right|}{E_{g a p}}
$$

Finally, the ampere-turns necessary when the machine is working in saturated conditions has to be calculated. Prior to this, the internal voltage $E_{p}$ is determined by using (17) and finally the total $m m f \theta_{\text {Ltot }}$ is evaluated as described in (18). In these equations, $X \sigma$ is the leakage reactance, $\theta_{F u}$ and $\theta_{F s}$ are the values of the unsaturated and saturated rotor Ampereturns, respectively.

$$
\begin{gathered}
\hat{E}_{P}=E_{a}+R_{a} \hat{I}_{a}+j X_{\sigma} \hat{I}_{a} \\
\theta_{L t o t}=\theta_{F s}-\theta_{F u}+\theta_{g u}
\end{gathered}
$$

By manipulating (15), the total number of Ampere-turns in $1 \theta$ operation can be determined as follows in (19), allowing for returning acceptable values of field current also for $1 \theta$ operation.

$$
\theta_{\text {Ltot }-1 \theta}=\frac{\theta_{\text {Ltot }-3 \theta}}{\sqrt{3}}
$$

In order to prove all the above, a detailed $\mathrm{FE}$ analysis of a baseline machine, i.e. the above-mentioned 400kVA SG, is carried out. This is discussed in the following section.

\section{FE ANALYSIS OF THE PLATFORM OPERATING AT MAXIMUM SINGLE-PHASE LOADING}

\section{A. The considered synchronous generator}

The salient-pole, wound-field, SG studied in this paper is a 4pole alternator, designed for operating at the rated values given in Table I.

TABLE I

MACHINE'S PARAMETERS

\begin{tabular}{c|c|c}
\hline $\mathrm{S}$ & $400 \mathrm{kVA}$ & Rated apparent power \\
\hline $\mathrm{V}$ & $400 \mathrm{~V}$ & Rated voltage \\
\hline $\cos \varphi$ & 0.8 & Power factor \\
\hline $\mathrm{f}$ & $50 \mathrm{~Hz}$ & Frequency \\
\hline $2 \mathrm{p}$ & 4 & Number of poles \\
\hline
\end{tabular}

The stator winding of the machine has a double-layer structure and is featured with a shortened pitch of $2 / 3$ to remove the triplen harmonics, which are disruptive for the $1 \theta$ operation of $3 \theta$ SGs. The winding configuration can be observed in Fig. 4, where a cross-section of the machine is shown and the phase A has been highlighted. There are 2 circuits in parallel on the stator winding, each of them is characterized by 8 coils. This is also visible in the crosssection of Fig. 3. Another major feature of the considered alternator is the skewing implemented on the stator stack. This is done with the aim of reducing the slotting effects and thus improving the output waveforms.

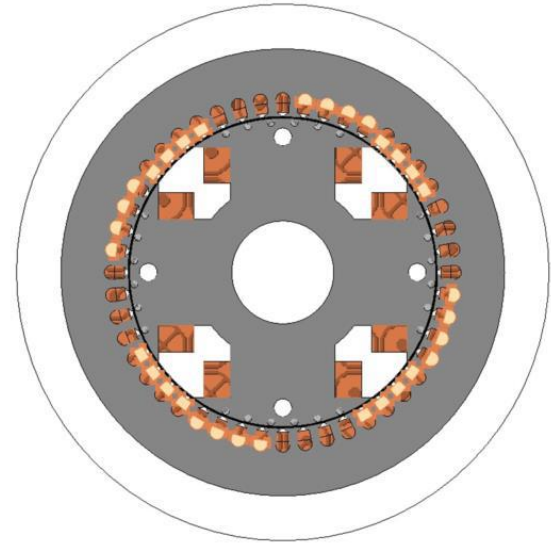

Fig. 3. 2-D model of the machine with phase A highlighted

The rotor of the studied machine is provided with damper bars embedded in the salient poles. In particular, there are 6 bars-per-pole, whose electrical continuity is guaranteed by short-circuiting aluminum end laminations. All these features are implemented in an appositely built FE model of the machine, whose details are given below. 


\section{B. The FE model}

Considering the features highlighted in the previous section (especially the one regarding the stator skewing), it is clear that a 3-D modelling would be ideal for the analysis of the $400 \mathrm{kVA}$ generator considered in this work. However, in order to reduce the inherent computational resources, a 2-D FE model of the platform is built, with the aim of simulating the machine behavior under $1 \theta$ loading. The cross-section of the modelled machine is shown in Fig. 3. Due to the importance of the damper cage during the $1 \theta$ operation, particular focus is given to the modeling of this additional rotor winding. In fact, in order to consider potential skin effects into the damper bars ensuing from the stator slot harmonics, each bar is modelled as a solid conductor, as suggested by [8] and [9]. The FE model is coupled to the in-built electrical circuits in the FE software, representing the stator phases, the rotor field winding and the damper cage. All the rotor bars are in parallel and short-circuited by simple circuital connections, while the $1 \theta$ operation is achieved by series-connecting the phases $\mathrm{A}$ and $\mathrm{C}$ of the stator winding, as shown in Fig. 4. Additional circuital components are used to account for the end-winding effects, i.e. the end-winding stator and rotor resistance.

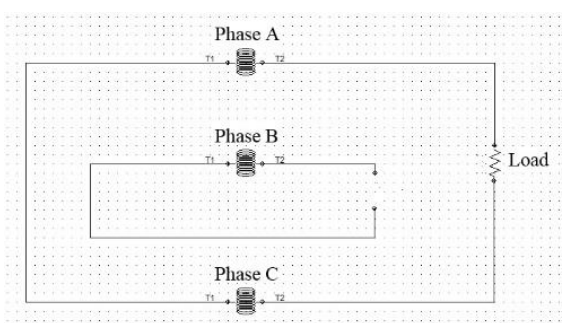

Fig. 4. Electrical circuit of the stator windings for simulating $1 \theta$ operation.

While at no-load operation, as mentioned in Sections II and III, the value of the excitation current is the same as in $3 \theta$ condition, a $m m f$ reduction has to be considered when a generic load is applied. This can be obtained by using and applying (19) to the current source that feeds the circuit coupled to the FE model and relevant to the field winding. Having set-up all the aspects highlighted above in the FE tool, transient with motion simulations are used for the analysis of the machine. In order to take into account the stator skewing, several slices of the generator are analyzed and separately solved $[10,11]$. These slices differ from each other for the different initial positions of the rotor with respect to the stator. To be consistent with the skewing feature, the initial position of each slice is a sub-multiple of the skewing angle. All the above is used for validating the preliminary sizing procedure described in Section II. The related comparative exercise is given in detail in the next sections.

\section{FE results and comparison at rated single-phase loading $(230 \mathrm{~kW})$}

Having implemented the FE model described in the previous section, it becomes now possible to compare the related results with the analytical ones. The comparison is carried out at rated, $1 \theta$ operation, with the load imposed by using circuital components whose values depend on the investigated operating point. The summary of this comparison is shown in Table II, where an excellent match between analytical and FE results can be observed.

TABLE II

MATCH BETWEEN ANALYTICAL AND FE MODEL

\begin{tabular}{l|c|c|c}
\hline & Analytical results & FE results & $\%$ \\
\hline & & & \\
\hline$V_{r m s}$ & $400 \mathrm{~V}$ & $413.6 \mathrm{~V}$ & -3.4 \\
\hline$I_{r m s}$ & $577.4 \mathrm{~A}$ & $596.9 \mathrm{~A}$ & -3.4 \\
\hline$P$ & $231 \mathrm{~kW}$ & $247 \mathrm{~kW}$ & -6.9 \\
\hline$I_{F-1 \theta}$ & $33.30 \mathrm{~A}$ & $28.9 \mathrm{~A}$ & 13.2 \\
\hline
\end{tabular}

For the sake of completeness, the voltage and current waveforms are shown in Fig. 5, while a field map of the generator under analysis is depicted in Fig. 6.
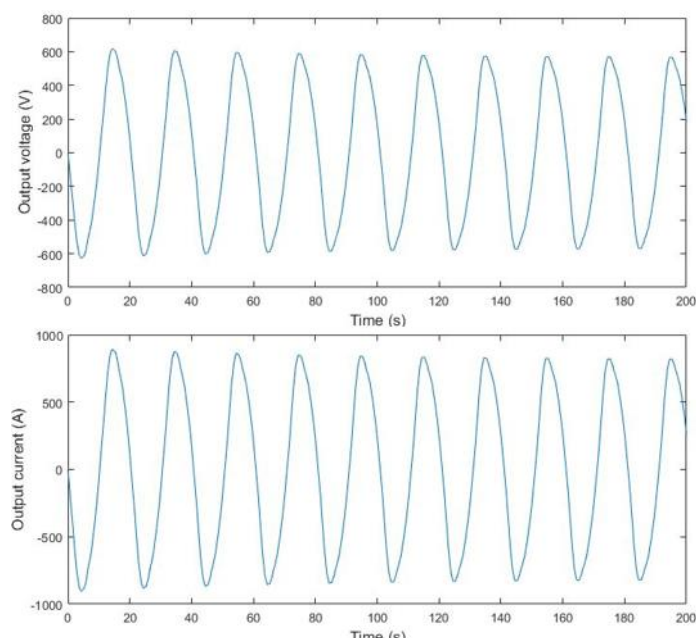

Fig. 5. Voltage and current waveforms of the $400 \mathrm{kVA}$ SG in $1 \theta$ operation,

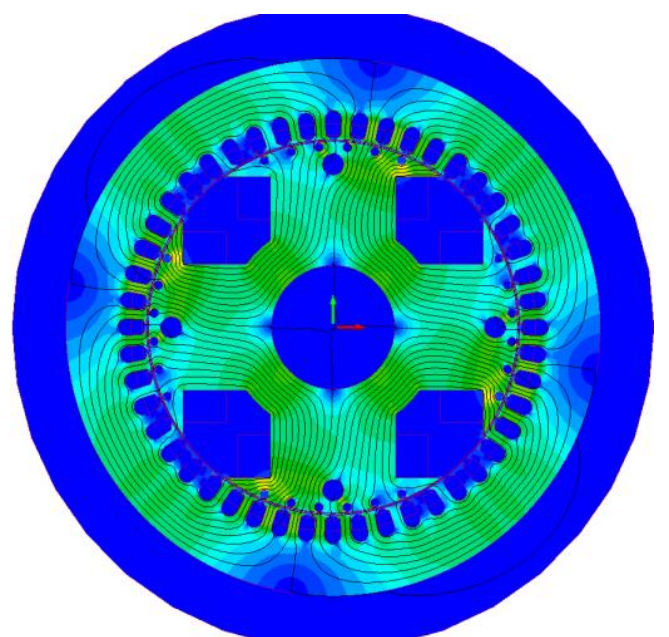

Fig. 6. Field map of the generator under analysis under $1 \theta$ rated load.

As explained in Section I, the presence of the damper cage plays a significant role in "damping" the negative sequence magnetic field during the particular considered $1 \theta$ operation. This results in high induced currents in the bars, with undesired additional losses and potential temperature issues [12]. Considering this, it is clear that at full-load, $1 \theta$ operation, the value of the damper cage losses is intolerable and it will produce overheating into the winding itself and on the whole rotor structure. In Table III, the bar losses along one pole are given, highlighting that these elevated values 
will not allow for a practical, safe testing of the SG under this studied load condition.

TABLE III

OHMIC LOSSES IN A ROTOR POLE

\begin{tabular}{c|c}
\hline Damper bars numeration & Losses [W] \\
\hline Bar1.1 & 270 \\
\hline Bar1.2 & 149 \\
\hline Bar1.3 & 123 \\
\hline Bar1.4 & 92 \\
\hline Bar1.5 & 152 \\
\hline Bar1.6 & 1051 \\
\hline
\end{tabular}

Considering all the above, the validated FE model is then used for analyzing reduced loading conditions, whose results are provided in the next section and compared with experimental measurements for validation purposes.

\section{FE results at $5 \mathrm{~kW}, 10 \mathrm{~kW}$ and $15 \mathrm{~kW}$}

Considering the excessive losses shown in the previous section (Table III), then, a preliminary FE analysis is performed in order to predict damper cage losses when the machine operates with lower load. The tests are performed by increasing the resistive load of Fig. 4 in steps of $5 \mathrm{~kW}, 10 \mathrm{~kW}$ and $15 \mathrm{~kW}$. The related results are shown in Tab. IV.

TABLE IV

OHMIC BAR LOSSES WITH 5KW, 10KW, 15KW RESISTIVE LOAD

\begin{tabular}{|c|c|}
\hline & Losses [W]at $5 \mathrm{~kW}$ load \\
\hline Bar1.1 & 19.92 \\
\hline Bar1.2 & 5.04 \\
\hline Bar1.3 & 2.15 \\
\hline Bar1.4 & 2.18 \\
\hline Bar1.5 & 6.12 \\
\hline \multirow[t]{2}{*}{ Bar1.6 } & 22.71 \\
\hline & Losses [W] at $10 \mathrm{~kW}$ load \\
\hline Bar1.1 & 19.95 \\
\hline Bar1.2 & 5.15 \\
\hline Bar1.3 & 2.32 \\
\hline Bar1.4 & 2.27 \\
\hline Bar1.5 & 6.78 \\
\hline \multirow[t]{2}{*}{ Bar1.6 } & 23.3 \\
\hline & Losses [W] at $15 \mathrm{~kW}$ load \\
\hline Bar1.1 & 20.1 \\
\hline Bar1.2 & 5.25 \\
\hline Bar1.3 & 2.62 \\
\hline Bar1.4 & 2.54 \\
\hline Bar1.5 & 7.65 \\
\hline Bar1.6 & 24.8 \\
\hline
\end{tabular}

\section{EXPERIMENTAL PLATFORM}

\section{A. Description of the platform}

In this section, the experimental set-up is described and measurements at reduced load and $1 \theta$ operation are carried out. The experimental platform of the particular SG considered in this paper consists of an induction machine drive, acting as the prime mover, whose speed loop controls the frequency of the SG, which is mounted on the same shaft of the motor. The stator winding is connected to a resistive load bank that can be remotely controlled and varied up to $200 k W(3 \theta)$. The experimental set-up can be observed in Fig. 7.

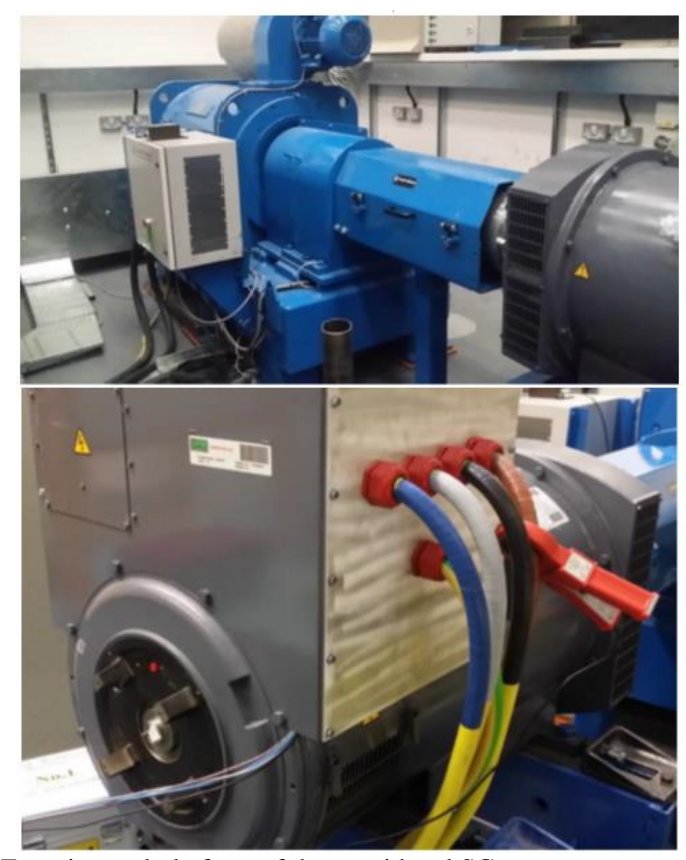

Fig. 7. Experimental platform of the considered SG.

\section{B. Experimental tests}

For the reasons explained in the previous section, the resistive load bank is varied from $3.27 \mathrm{~kW}$ to $18.58 \mathrm{~kW}$. The load voltage is controlled by the user (through the DC power supply) in order to be kept at its rated value of $400 \mathrm{~V}$. Test measurements can be observed in Table V.

TABLE $V$

EXPERIMENTAL TEST IN $1 \theta$ OPERATIONS

\begin{tabular}{c|c|c}
\hline $\mathrm{V}[V]$ & $\mathrm{I}[A]$ & $\mathrm{P}[k W]$ \\
\hline 398 & & 3.27 \\
\hline 400 & 8.22 & 6.54 \\
\hline 399 & 16.35 & 9.29 \\
\hline 399 & 23.28 & 12.4 \\
\hline 399 & 31.1 & 15.47 \\
\hline 399 & 38.77 & 18.58 \\
\hline
\end{tabular}

FE tests are also carried out to compare the results with those experimentally evaluated and shown in Table V. The comparison between FE and experimental results with equal rated voltage of $400 \mathrm{~V}$ are shown in Table VI, with an excellent similarity being achieved.

TABLE VI

COMPARISON BETWEEN EXPERIMENTAL AND FE RESULTS

\begin{tabular}{c|c|c}
\hline FE & Experimental & $\%$ \\
\hline $3.34 \mathrm{~kW}$ & $3.27 \mathrm{~kW}$ & 2 \\
\hline $6.67 \mathrm{~kW}$ & $6.54 \mathrm{~kW}$ & 2 \\
\hline
\end{tabular}

\section{CONCLUSION}

This paper investigated the potential of using a $3 \theta \mathrm{SG}$ in $1 \theta$ operating condition, with special focus on the analytical evaluation of the field current and a detailed FE analysis of the damper cage losses during such operation. As vessel to investigate this study, a $400 \mathrm{kVA}$ SG was used. First, an analytical evaluation of the expected performance at maximum rating $(230 \mathrm{~kW})$ and unity power factor has been 
carried out and then compared with FE results, showing an excellent match. In this particular operating condition, focus was given to the damper cage currents and its associated losses. As expected, due to the necessity to "damp" the negative sequence armature field, the full-load damper winding losses are about ten times the correspondent ohmic losses in $3 \theta$ condition. Therefore, intolerable temperature issues on the rotor can be present. Considering this, preliminary $\mathrm{FE}$ analyses have been performed in order to identify the limits at which the rotor losses do not cause any irreversible damage to the machine. Hence, experimental measurements have been carried out at reduced loading on the test bench of the SG prototype being investigated in this work. A purely resistive load bank was used to test the machine under $1 \theta$ condition, with 2 phases being utilized and one phase disconnected. The test results have been finally performed at constant stator output voltage, showing an excellent match with FE results and proving the validity of the proposed methods. Considering all the above, it is clear that there is still room for improving the design of SGs, when they are designed for optimally operating also in $1 \theta$ condition. Future work will focus on re-designing the damper winding of the analyzed generator, aimed at finding an optimal solution in terms of accomplishments at $3 \theta$ operation and loss reduction in $1 \theta$ condition.

\section{REFERENCES}

Renjit, A.A., M.S. Illindala, and D.A. Klapp, Graphical and Analytical Methods for Stalling Analysis of Engine Generator Sets. IEEE Transactions on Industry Applications, 2014. 50(5): p. 2967-2975.

Waters, W.L., Modern development in single-phase generators. Proceedings of the American Institute of Electrical Engineers, 1908. 27(5): p. 579-586.

Laldin, O., S.D. Sudhoff, and S. Pekarek, Modified Carter\&\#x0027;s Coefficient. IEEE Transactions on Energy Conversion, 2015. 30(3): p. 1133-1134.

Honsinger, V.B., Sizing Equations for Electrical Machinery. IEEE Power Engineering Review, 1987. PER-7(3): p. 39-40.

Huang, S., et al. A general approach to sizing and power density equations for comparison of electrical machines. in Industry Applications Conference, 1996. Thirty-First IAS Annual Meeting, IAS '96., Conference Record of the 1996 IEEE. 1996.

Bianchi, N., S. Bolognani, and P. Frare, Design criteria for highefficiency SPM synchronous motors. IEEE Transactions on Energy Conversion, 2006. 21(2): p. 396-404. design tool for brushless excitation systems of low-medium rated synchronous generators. in 2016 19th International Conference on Electrical Machines and Systems (ICEMS). 2016.

Nuzzo, S., et al., Improved Damper Cage Design for SalientElectronics, 2016. PP(99): p. 1-1.

Nuzzo, S., et al. Damper cage loss reduction and no-load voltage THD improvements in salient-pole synchronous generators. in 8th IET International Conference on Power Electronics, Machines and Drives (PEMD 2016). 2016.

Williamson, S., T.J. Flack, and A.F. Volschenk, Representation of skew in time-stepped two-dimensional finite-element models of electrical machines. IEEE Transactions on Industry Applications, 1995. 31(5): p. 1009-1015.

Gyselinck, J.J.C., L. Vandevelde, and J.A.A. Melkebeek, Multislice FE modeling of electrical machines with skewed slots-the skew discretization error. IEEE Transactions on Magnetics, 2001. 37(5): p. 3233-3237.

Bassi, C., D. Giulivo, and A. Tessarolo. Transient finite-element analysis and testing of a salient-pole synchronous generator with different damper winding design solutions. in The XIX International Conference on Electrical Machines - ICEM 2010. 2010.
Nuzzo, S., et al. An analytical and genetic-algorithm-based Pole Synchronous Generators. IEEE Transactions on Industrial

\section{BIOGRAPHIES}

Cosimo Spagnolo received his B.Sc. degree in Electronic Engineering from the University of Messina, Messina, Italy, in 2013 and M.Sc. degree in Electrical Engineering from the University of Bologna, Bologna, Italy, in 2016. He is currently a Ph.D. student and Marie-Curie Early Stage Researcher at the Institute for Aerospace Technology Centre at the University of Nottingham and also member of PEMC (Power Machine and Control Group). His current research interests include the analytical approach to design of electrical distribution systems for aircraft.

Stefano Nuzzo received his B.Sc. and M.Sc. degrees in Electrical Engineering from the University of Pisa, Pisa, Italy, in 2011 and 2014, respectively. He is currently a Ph.D. student with the Power Electronics, Machines and Control Group, The University of Nottingham, Nottingham, U.K. He spent six months with The University of Nottingham as a Visiting Student in 2013, where he was involved in developing analytical and numerical models for the analysis of permanent magnet synchronous machines. His current research interests include the analysis and design of salient-pole synchronous generators and brushless excitation systems.

Giovanni Serra received the M.Sc. degree (with honors) in electrical engineering from the University of Bologna, Bologna, Italy, in 1975. He joined the Department of Electrical Engineering, University of Bologna, first as a recipient of a Fellowship of the National Research Council, then as a Research Associate, and, since 1987, as an Associate Professor. He is currently Professor of electrical machines in the Department of Electrical Engineering. He has authored more than 180 papers published in technical journals and conference proceedings. His fields of interests are electrical machines, electrical drives, and power electronic converters. His current activities include multiphase drives, direct torque control of ac machines, linear motors, and ac/ac matrix converters. Dr. Serra is Associate Editor of IEEE Transaction on Industrial Electronics and of IEE Electric Power Applications. He is a Member of the IEEE Industry Applications, IEEE Dielectrics and Electrical Insulation, IEEE Industrial Electronics Societies, and of the Italian Electrotechnical and Electronic Association.

Chris Gerada (M'05) received the Ph.D. degree in numerical modeling of electrical machines from The University of Nottingham, Nottingham, U.K., in 2005. He subsequently worked as a Researcher with The University of Nottingham on high-performance electrical drives and on the design and modeling of electromagnetic actuators for aerospace applications. Since 2006, he has been the Project Manager of the GE Aviation Strategic Partnership. In 2008, he was appointed as a Lecturer in electrical machines; in 2011, as an Associate Professor; and in 2013, as a Professor at The University of Nottingham. His main research interests include the design and modeling of high-performance electric drives and machines. Prof. Gerada serves as an Associate Editor for the IEEE TRANSACTIONS ON INDUSTRY APPLICATIONS and is the Chair of the IEEE IES Electrical Machines Committee.

Michael Galea received his $\mathrm{PhD}$ in electrical machines design from the University of Nottingham, UK, where he has also worked as a Research Fellow. He is currently a Lecturer in Electrical Machines and Drives within the PEMC research group of the University of Nottingham. He is the Deputy Director of the Institute for Aerospace Technology at the University of Nottingham, where he is also a Lecturer in Aerospace Systems Integration and where he manages a number of diverse projects related to the more / all electric aircraft and associated fields. His main research interests are design, analysis and thermal management of electrical machines and drives and the more electric aircraft. 